their patient data into maps that demonstrate who and where they serve, where access to healthcare remains poor, and how social determinants of health affect their communities. ABFM leaders helped develop those tools and now want to offer them to all family physicians. The ABFM is proposing to work with the Graham Center and HealthLandscape, its sister center in the AAFP, to develop the Population Health Assessment Tool (PHAsT). Family physicians enrolled in the registry would have the option of using PHAsT to define their clinical service area, understand which neighborhoods are most dependent on them, look at disease and quality clusters ('hotspots'), and to draw on social determinant data to develop community vital signs for patients, and to look at risk of poor health across their community. Value-based payments mean greater accountability for population health, and most family physicians lack tools or the ability to use their data to inform this role. Many family physicians are also frustrated by patients who cannot or won't take their medication or change health behaviors, often because they don't understand what is going on in their patients' lives, or because they don't know who to partner with in the community to help their patients. PHAsT aims to help family physicians do population health better, and to improve understanding of community supports. For example, PHAsT may help you recognize that most of your patients with diabetes and hemoglobin $\mathrm{A}_{1 \mathrm{c}}$ above 9.0 live in neighborhoods that are unsafe for exercise and lack healthy food sources. You could partner with a local YMCA, mall or armory to develop an indoor walking club, diabetes peersupport group, or farmers market-or all 3. We know from experience that family physicians in community health centers have used these tools in clever ways, and now want all family physicians to have the same opportunity, especially when payments may soon be based on population health outcomes.

\section{In Invitation}

TRADEMaRQ, DAIQUERI and PHAsT are a collective commitment that the ABFM is making to make MOC less burdensome, more meaningful, and a source of information that supports understanding and improvement in family medicine. This registry and its tools aim to help you do the right thing, at the right time, and earn more for it. The ABFM is actively seeking partners to help turn clinical data into tools that enhance primary care's impact on health. We welcome questions, concerns, advice, or offers to collaborate.

Robert L. Pbillips, Jr., MD, MSPH American Board of Family Medicine

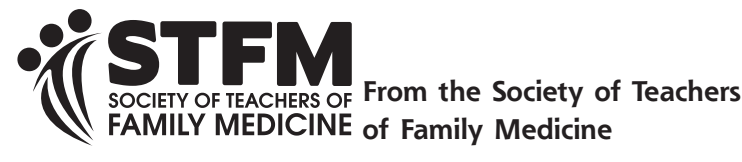

Ann Fam Med 2015;13:290-291. doi: 10.1370/afm.1800.

\section{STFM LAUNCHES INITIATIVE IN RESPONSE TO FACULTY SHORTAGE}

Program directors and department chairs have bemoaned the fact that they can't fill open faculty positions. The shortage is projected to get even worse as the demand for family physicians increases due to the aging population, population growth, incentives for preventive care, and a growing number of insured Americans. ${ }^{1}$

STFM leadership has identified a number of challenges in recruiting and retaining a sufficient cohort of family medicine faculty:

- There's a substantial salary differential between private practice and academic practice

- At many institutions, there's a lack of support for faculty time; instead work hours are increasing and salaries are stagnating

- Residency graduates assume or have been told that they should go into private practice before becoming faculty

- Those moving from private practice to faculty may not have the teaching skills, scholarship skills, OB skills, etc. that are needed for teaching; fewer physicians in practice are doing the things that need to be taught

- There aren't enough family physicians, so there's not a big base to pull from

- Some residents don't have good faculty role models

\section{Faculty for Tomorrow}

STFM is responding to this dearth of family medicine educators with a new initiative funded by the STFM

Foundation. The 2-year initiative, called "Faculty for Tomorrow," will:

- Expand STFM's formal faculty recruiting efforts of residents

- Provide resources and training for new faculty, including those moving from private practice to family medicine education

- Identify and support young family physicians with leadership potential

- Ensure leaders of institutions understand the time and competencies required to be faculty

The Foundation will raise funds for the initiative, through donations from individuals and outside funders, through April of 2016. A task force will begin planning in summer/fall of 2015. The initiative will run through 2017. 
Faculty for Tomorrow will provide a training opportunities to reach a broad group of residents and faculty. Deliverables will include:

\section{Residents as Teachers Training}

- Full-day preconference sessions at the 2016 \& 2017 STFM Annual Spring Conference for residents interested in careers in academic family medicine

- Enhanced web content for residents on stfm.org and TeachingPhysician.org, including how and why to become faculty

- Development and dissemination of Residents as Teachers curriculum for use at individual residency programs, regional meetings, or AAFP chapter meetings

- A resident track of online modules on components of teaching

- "From residency to faculty" messaging/campaign/ education

\section{Resources and Training for New Faculty}

Development of a virtual training track for new faculty that will include online modules and quarterly webinars/calls
Communication About What it Means and What it Takes to be Residency/Medical School Faculty Dissemination of and advocacy for criteria for excellence in family medicine education. This includes the sharing of information-through articles, presentations, blog posts, etc.- on competence, time, and training required to be an excellent residency program and/or medical school. The intent is to help residency and medical school faculty get institutional support (program funding, salaries, and/or dedicated time) to effectively do their jobs and also achieve work/life balance. The communications would also encourage appropriate exposure to excellent and inspiring role models throughout the continuum of medical education and recommend systemic efforts to respond to the "hidden curriculum," including bias and "trash talk" about specialty choice.

To learn more or make a donation, visit http://www. stfm.org/foundation.

\section{Reference}

1. Petterson SM, Liaw WR, Phillips RL Jr, Rabin DL, Meyers DS, Bazemore AW. Ann Fam Med 2012;10(6):503-509. 